\title{
A NCRE-oriented Teaching Mode
}

\author{
Yujuan Li \& Mei Wang \\ College of Information Engineering, Taishan Medical University \\ Tai'an 271016, China \\ E-mail: liyujuan_1978@163.com
}

Zhunan Zhou

College of Information Science and Engineering, Shandong Agricultural University

Tai'an 271018, China

Received: March 29, 2011

Accepted: April 14, 2011

doi:10.5539/cis.v4n3p181

\begin{abstract}
NCRE (National Computer Rank Examination) rating certificate has been regarded as one of important referenced hardware indexes to employ undergraduates by more and more enterprises and the most difficult point to get this certificate is the computer programming. The traditional teaching mode of computer programming emphasizes more theories but not practices, and students often lacked in the capacity to solve practical problems. In the teaching of computer programming, three methods including the situational language teaching method which can fully mobilize students' study enthusiasm, the case teaching method which can enhance teachers' comprehensive quality and help teachers to select and work out cases, and help students to comprehensively grasp knowledge, and the network teaching platform which can strengthen the communication between teachers and students, should be dynamically integrated to arouse students' study interests, and help them study more actively.
\end{abstract}

Keywords: NCRE, Situational language teaching, Case teaching, Network teaching platform

\section{Introduction}

In recent years, the technology of computer programming has been widely applied in many domains of China, and to fit for the development demand of the knowledge economy and the information industry, the technology of computer programming has been one of necessarily basic skills for undergraduates in many majors. Many enterprises regard NCRE (Zhai, 2008, P. 64-66) as one of important referenced hardware indexes to employ undergraduates, because it can reflect undergraduates' theoretical knowledge and professional knowledge of computer and their capacity to develop and maintain the computer information system and application system to some extent. Therefore, the research of the NCRE-oriented computer programming teaching mode can strengthen undergraduates' practical ability of computer programming, and enhance the passing rate of NCRE and students' employability.

\section{Analysis of the present teaching mode of computer programming}

At present, most colleges in China adopt the traditional teaching method of grammar instruction when teaching the course of computer programming (Qiao, 2009, P. 54-55). Traditional teaching mode only emphasizes the theory but ignores the practice, and the joint relevance of knowledge points is weak, and students' practical ability is bad, and they only understand the basic concepts on the shallow layer, and students lack in the ability in the practical application and the transverse association of knowledge, and once they encounter practical problems, they often lose their bearings. The deficiency of this ability will make the classroom become boring, and students will lose the study interests, which is far from the enterprises' demand for undergraduates.

\section{Discussion and research of the NCRE-oriented computer programming teaching mode}

\subsection{Introducing the situational teaching to fully mobilize students' study enthusiasm}

For those students who just touch the computer programming, it is a strange course, and they have not ideas to solve problems by programming, so most students think that the computer programming is an abstract course, and they don't know how to use this technology. Rogers said that "the practical problems in the life are the most meaningful study for students, and only when facing real situation, students will solve the problem heart and soul 
(Cheng, 2009, P. 4950-4951)". Therefore, teachers can create the applicable exploration situation and lead students to solve actual problems by programming.

For example, when we take money from the ATM, the password should be tested to prevent others using our accounts. So teachers can lead students to discuss how to realize the password check program and how to accomplish the password checking. Because these things are familiar in daily life, so students' study interest will be enhanced largely, and they will actively discuss the process of password checking.

First, user inputs the password according to the hint.

Second, the system will check the password, and if the password is right, user can implement the new operation, and if the password is wrong, the system will display the information of mistake, and the system will hint the user to input the password again, and check the password again.

Generally, user can input the password three times, and only if the password is right once, the user can continue the operation, and if the passwords are all wrong, the card will be locked.

By analyzing this process, teachers can lead students to consider the realization of this process and the design and implementation of the algorithm by computer programming.

\subsection{Implementing NCRE-oriented case teaching}

The case teaching is a kind of teaching method to study by simulating or reproducing some situations in the real life and bringing students into the case situation to discuss the problem. In the teaching of computer programming, the case teaching method can compensate some deficiencies in the teaching of computer programming. How to effectively use this teaching method and enhance the teaching method, following aspects should be analyzed.

First, teachers' comprehensive quality should be enhanced.

The case teaching needs higher professional teachers, and to enhance teachers' comprehensive quality is the top priority for the case teaching. Teachers should not only know abundant theoretical knowledge, but also grasp certain practical experiences and operation skills.

Second, cases should be selected and formed carefully.

To utilize the case teaching method in the NCRE-oriented teaching, the selection of case is very important, and the quality of case will directly influence the teaching effect. For the selection of case, following points should be emphasized.

(1) Cases should be appropriate, proper, and representative, can reflect the emphases and difficulties of teaching, and contain relative knowledge points of the course.

(2) Cases should advance with the times, so teachers should collect real problems in old NCRE examples, and select those representative examination questions in them to explain for students.

(3) Cases should be associated with NCRE, so students can more deeply know NCRE.

(4) Cases should be systematic, and most cases used in the NCRE-oriented computer programming teaching process should be associated each other, and be ranked for the easier to the more advanced, which can help students to grasp relative knowledge.

\subsection{Fully utilizing the network resources to strength the interactive teaching between teachers and students}

In China, with the popularization of computer and the development of the network technology, more and more colleges and education institutions use the network environment to strengthen the teaching effect, and the network teaching platform used in the university (Wang, 2010, P. 100-102) is one representative application, and in the practice, the platform has been widely appraised by teachers and students, and the NCRE-oriented computer programming teaching can also fully utilize the network resources to strengthen the emotional communication and interaction between teachers and students. To achieve above intentions, following teaching methods are used to enhance the effect of interactive teaching in the network environment (An, 2004, P. 106).

(1) Based on relative study theories, teaching theories, and spread theories, the basic grammar knowledge and common programming method of computer programming are introduced, and the results are compared and evaluated.

(2) By the case analysis, the detailed problems in the cases are deeply discussed (Why we do this? What situation we should do this? What effect will achieve?), and students understandings about teaching mode will be further strengthened. 
(3) By taking in students' feedback information at any time, the emotional communications between teachers and students can be further strengthened through questionnaire, question answer, and discussion, students' study interests about the course will be enhanced.

(4) Teachers should arrange certain homework to students and correct the homework in time, so they can grasp students' grasping degree to the knowledge.

(5) Teachers can issues online tests at regular intervals to grasp students' study schedule and adjust the teaching mode in time.

\section{Conclusions}

Computer programming is a course integrating theory and application, and the in the study process of this course, the theory is the base, and the application is the intention, and there are varied teaching modes for this course. The NCRE-oriented teaching mode of computer programming is discussed and studied in this article, which integrating three methods including the situational teaching, the case teaching, and the network teaching platform, and this mode is the meaningful exploration and practice from the teaching direction giving priority to students, and can further enhance the teaching effect of the course of NCRE-oriented computer programming.

\section{References}

An, Yueguo \& Che, Zhigang. (2004). Introspection of the Classroom Teaching Practice in the Network Environment. Educational Informationization. No. 10. P. 106.

Cheng, Weili \& Chen, Lili. (2009). Creation of the Exploration Teaching Situation in the Course of Computer Programming. Computer Knowledge and Technology. No. 5(18). P. 4950-4951.

Franciska Bothma JL Dk Monteith. (2004). Self-regulated learning as a prerequisite for successful distance learning. South African Journal of Education. No. 12. P. 31.

HulshofCD, Wilhelm P, Beishuizen JJ, van Ri jn H. (2005). A tool for the study of inquiry learning. Computers in Human Behavior. No. 21(6). P. 945-956. Nov. of 2005.

Qiao, Xiaolin. (2009). Discussion of the Teaching Method Selection Based on Action System. Journal of Changchun University of Science and Technology. No. 4(4). P. 54-55.

Wang, Mei, Li, Yujuan \& Wang, Ge. (2010). Study on Realizing the Interactive Teaching between Teachers and Students. Modern Education Technology. No. 20(13). P. 100-102.

Wang, Shanqin. (2009). Application of the Case Teaching Method in the Teaching of Higher Vocational Programming. Journal of Chuzhou University. No. 11(3). P. 69-71.

Zhai, Yinshan. (2008). Reform and Development of National Computer Rank Examination under New Circumstance. Journal of Hebei Software Institue. No. 10(4). P. 64-66. 